\title{
AGNIETÉ ŽOTKEVIČIŪTĖ-BANEVIČIENĖ
}

Generolo Jono Žemaičio Lietuvos karo akademija, Lietuva

General Jonas Žemaitis Military Academy of Lithuania, Lithuania

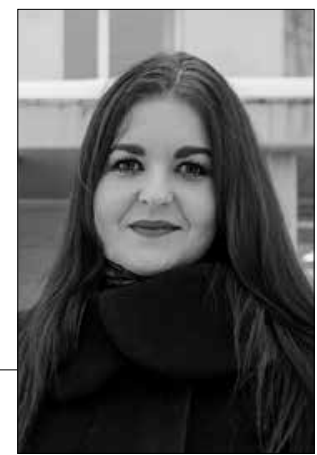

\section{KULTÜRINIS VEIKSNYS ŠIUOLAIKINĖJE KARYBOJE \\ The Cultural Element in the Modern Warfare}

\begin{abstract}
SUMMARY
The article aims to review the change in the security environment after the Cold War. This change led to the growing importance of the cultural element in warfare and its inclusion in the military planning This element reflects the increase in the importance of soft power in the current interpretation of state and military power and can be related to the expanded range of military operations. The first part discusses how the cultural element in modern warfare has become part of the military arsenal. More specifically, it discusses the influence of the security environment and the new war paradigms that explain this change. The second part analyses the changes in the concept of the soldier and the need for a soldier diplomat in modern warfare. This need reflects the establishment of the cultural element and of cultural competences of military personnel both in the scientific and the military context.
\end{abstract}

\section{SANTRAUKA}

Straipsnyje analizuojama saugumo aplinkos kaita po Šaltojo karo, lèmusi kultūrinio veiksnio svarbos karyboje didejjimą bei jo įtraukimą i karinį planavimą. Kultūrinis veiksnys atspindi bendrą minkštojo galios elemento reikšmės didejjimą dabartiniame valstybės ir karinès galios aiškinime ir gali būti siejamas su išplèstu karinių operaciju spektru. Pirmoje straipsnio dalyje analizuojama, kaip kultūrinis veiksnys šiuolaikinèje karyboje tapo karinio arsenalo dalimi ir, konkrečiai, saugumo aplinkos ir ją aiškinančių naujuosius karus apibrèžiančių paradigmu i̇taka šiam pokyčiui. Antroje dalyje analizuojami kario koncepcijos pokyčiai ir kario diplomato funkciju poreikis šiuolaikinèje karyboje, atspindintis kultūrinio veiksnio, kaip karių kultūrinių kompetencijų visumos, įsitvirtinimą ne tik moksliniame, bet ir kariniame kontekste. 


\section{IVADAS}

Socialistinės sistemos žlugimas Rytu Europoje ir vèliau sekęs pačios Sovietu Socialistiniu Respublikų Sajungos iširimas sąlygojo tarptautinę saugumo transformaciją. Šaltojo karo metu didelę itaką gynybiniu pajėgu planavimui turèjo tarptautinès sistemos dvipoliškumas ir branduolinio ginklo grèsmė, kuriuos po Šaltojo karo ir, ypač po $2001 \mathrm{~m}$. rugsejjo 11-osios teroristiniu išpuoliu, strateginiame planavime pakeite suvokimas, jog šiuolaikineje tarptautinejje sistemoje kylančios grèsmès yra daugialypès. Poreiki keisti ginkluotuju pajègu operacijų spektrą dar labiau skatino didejjantis Vakaru valstybiu isitraukimas i pasirenkamuosius karus (angl. wars of choice) ${ }^{1}$. Atsižvelgiant i saugumo aplinkos keliamus iššūkius ir daugialypi grèsmiu pobūdị, Vakarų valstybėse išplèstas karinių operacijų spektras, ittraukiant ne tik branduolinį atgrasymą ir labai intensyvias kovas, bet ir karines operacijas, kitokias nei karas (angl. Military Operations Other Than War), humanitarinès pagalbos operacijas (angl. humanitarian assistance) ir pagalbą kritinių nelaimių metu (angl. disaster relief) (Segal 2005: 275). Apibūdinant pasikeitusi valstybiu atsaką i saugumo aplinkos keliamus iššūkius, JAV imtas naudoti terminas "plataus spektro dominavimas" (angl. full spectrum dominance) (Dorman et al 2002: 6-8).

Šaltojo karo metu kertinis saugumo užtikrinimo įrankis buvo kariniai pajègumai, pirmiausia, dèl branduolinio ginklo grèsmès, todèl nematerialūs karybos elementai, tokie kaip kultūrinis veiksnys, į karybą buvo įtraukti ribotai. Viena vertus, sovietologijos plètra JAV ir kitose NATO bloko valstybėse skatino analizuoti įvairias komunistinio bloko kultūras bei sudarè sąlygas išsamiau tyrinèti ideologines, politines ir strategines nuostatas bei veiksmus (žr. Bonnell, Breslauer 2002), taip pat ir strateginès kultūros, kariuomenių kultūros analizè laipsniškai tapo svarbiu elementu aiškinant tarptautinius santykius (žr. Archer 2003: 32-41; Carroll 2005: 62-69). Kita vertus, kultūrinio veiksnio, kaip kariu kultūrinių kompetencijų ${ }^{2}$ visumos, analizè tuo metu dar nebuvo svarbi kariniu mokymu ar pratybų dalis. Šiu kompetenciju poreikis planuojant ir igyvendinant karinius veiksmus itin išryškejjo tik po Šaltojo karo.

Pasibaigus Šaltajam karui branduolinio galios balanso svarba sumenko, be to, didelio masto konvencinis didžiujju valstybiu ar aljansų karas tapo gana neittikètinas. Priešingai, skirtingo asimetrinio laipsnio ir intensyvumo mažieji karai, taikos palaikymo ir nekarinès armijų misijos igijo svarbą kariniame planavime. Karinių intervencijų didejjimas, tarptautinio terorizmo augimas turejo didelę itaką strateginio, operacinio ir taktinio mąstymo kaitai Vakarų valstybių kariuomenèse (Bredow 2006: 170171). Rugsèjo $11 \mathrm{~d}$. išpuoliai sudare sąlygas revoliuciniam JAV nacionalinio saugumo politikos pokyčiui. Tapo svarbus kultūrinis veiksnys (Buley 2007: 84-85). NATO ir JAV kariniu operaciju Irake ir Afganistane problemos dar labiau aktualizavo kultūrinio dèmens karyboje reikšmę: poreikis pažinti sociokultūrinius veiksnius tapo pagrindine tema tarp karių, grižusių iš karų Afga- 
nistane ir Irake (žr. Petraeus 2006). Kartu plètojosi moksliniai tyrimai, patvirtinantys, jog šiuolaikinëje karyboje neįma- noma atsiriboti nuo sociokultūriniu skirtumu ir ju ittakos tarptautinėse operacijose (žr. Archer 2003: 2-12).

\section{KULTŪRINIS POSŪKIS KARO STUDIJOSE}

Karo ne tik kaip karinio, politinio ar socialinio, bet ir kaip kultūrinio fenomeno suvokimas vis labiau aktualizuojamas. Anot Johno Keegano, karas - kultūrinis fenomenas, o ne tik politikos tąsa, tai tam tikros bendruomenès kultūros išraiška (Keegan 1994). Šiandieninis kultūrinis posūkis karo studijose laikomas „kultūros pavertimu ginklu“ (angl. weaponization of culture): „tai, kad kultūrinis posūkis karyboje pasiekè pati Vakaru gynybos mąstymo branduoli, atspindi tradicinio karinio planavimo pokyčius. Tokioje situacijoje technologijos ir atstumas neteko svarbos, o kultūrinis veiksnys įžengè i̇ karinio mąstymo arsenalą" (Footitt 2016: 210). Patrickas Porteris pažymi, kad šiandienineje karyboje karo strategams vis dažniau prireikia antropologinių ir sociologinių žinių. Devinto dešimtmečio JAV karinèje strategijoje akcentuojamas technologinis pranašumas, tinkamas konvencinems kovoms, tačiau JAV nebuvo pasiruošusi poinvazinei veiklai, pavyzdžiui, Irake išlaikyti kontaktą su vietiniais gyventojais.

Karo strategu teigimu, atsižvelgiant i kariniu technologijų revoliucijų trūkumus, prasideda kultūros kontrrevoliucija, skatinanti suprasti sąveiką tarp žmonių kovos būdų ir jų tradicijų, identiteto, religijos, kolektyvinès atminties, nuostatų ir ipročiu (Porter 2007: 47). Koenas Stroekenas plètoja antropologijos ir kariuomenès sąveikos klausimą analizuodamas, kaip kultūra gali būti išnaudojama kaip dar vienas ginklas kare. Kultū- rinio veiksnio analizės ittraukimas i karinių veiksmų planavimą sudaro prielaidas formuoti prevencines priemones, padedančias suvaldyti sukilimus ar plètoti sąveiką su vietiniais šalies, kurioje vykdoma tarptautinè operacija, gyventojais (Zafar 2016: 34-35), ir žymi poslinki nuo ì valstybę orientuotos karybos (angl. state-centric warfare) prie i gyventojus orientuotos karybos (angl. population-centric warfare).

Iprastai kultūrinio veiksnio karyboje tyrimai apima galios generavimo procesus - strateginès kultūros, organizacinès, iskaitant kariuomenès, kultūros analizę. Pavyzdžiui, kariuomenès kultūros analizè leidžia atskleisti, ką kariuomenès galvoja apie save, kokios karo ir kovos koncepcijos vyrauja kariuomeneje (Lynn 2003: xix). Karinès kultūros tyrimai atskleidžia, kaip nacionalinėms ar organizacinèms bendruomenèms būdingos normos sukūrè šioms bendruomenèms būdingus elgesio modelius, tokius kaip nacionaliniai strateginiai stiliai ir organizaciniai kovos metodai (Farrell, Terriff 2002: 7). Karinès kultūros analizè atskleidžia kariuomeniu ypatybes, darančias įtaką kariuomenès elgesio būdams mūšio lauke ir atitinkamai karinès galios kaitai - jos didèjimui ar mažèjimui. Karių kultūrinès kompetencijos - vienas naujausių kultūrinio veiksnio karyboje aspektu - apima kitokią kultūrinio veiksnio analizès krypti - kariuomenès įsisavinamus (kitos kultūros) elgesio modelius, didinančius karinę galią (žr. Rosen 1996; Kier 1997; Far- 
rell 2005). Taigi, nors kultūrinis veiksnys karyboje nèra naujas elementas per se, tik po Šaltojo karo kultūrinis veiksnys kaip karių kultūrinių kompetencijų visuma pradedamas sieti su karinès galios didèjimu - priskiriamas karinès galios daugikliams (angl. force multiplier) ir imamas institucionalizuoti karinèse doktrinose (žr. Spencer 2009: 96-106).

Kultūrinis veiksnys šiuolaikinèje karyboje gali būti siejamas su naujuosius karus aiškinančiu paradigmų iškilimu. Šių paradigmų šalininkų teigimu, naujieji karai nèra totaliniai karai, tai - asimetriniai, neintesyvūs konfliktai, kuriuos dažniausiai sukelia nacionalistiniai, etniniai, religiniai ir kultūriniai veiksniai (žr. Herfried 2007; Kaldor 2005; Munkler 2005). Kitaip tariant, susiduriama su vadinamaisiais tapatybės karais (Antczak 2018: 200).

Asimetrija karyboje yra vienas pagrindinių naujujų karų bruožų (Munkler 2003: 7). Nors karų asimetriškumas nèra naujas reiškinys, nes „tam tikra prasme visas karas yra asimetrinis, niekada nèra identiškų priešininkų" (Pfanner 2005: 149), tačiau šiuolaikinëje saugumo aplinkoje skirtumai tarp kovojančių pusių yra didesni nei anksčiau. Pavyzdžiui, JAV turi gero lygio kariuomenę, kurią galima greitai dislokuoti visame pasaulyje, tačiau karai Afrikoje, Vidurio Rytuose ir kituose žemynuose išryškino, jog lemiamas veiksnys karyboje buvo ne aukštųjų technologiju ginklai, o gebejjimas sumažinti priešo karinę galia, atrandant ir išnaudojant jo silpnąsias puses (Pfanner 2005: 168).

Naujuosius karus apibrèžiančių paradigmų šalininkai siekia paaiškinti, kodèl tradicinis karinis mąstymas turi ribotą vertę šiuolaikinių ginkluotų konf- liktų kontekste, ir kokie pokyčiai turi būti vykdomi prisitaikant prie šiuolaikinių karų. Pergalè tokiuose konfliktuose negali būti grindžiama tik kariuomenès materialiais ištekliais; daug dažniau pergalè priklauso nuo kariuomenès gebèjimo sumažinti visuomenės paramą priešininkui. Vakarų karinės pajègos neišnaudoja savo karinio potencialo, kadangi veikia pagal karo principus ir doktrinas, pabrèžiančias manevrinės karybos, pavyzdžiui, blitzkrieg, svarbą (Lind 2008: 13-20). Naujujų karų šalininkai èmèsi identifikuoti būtinus pokyčius karyboje, kurių vienas pagrindinių - atnaujinta širdžių ir protų laimèjimo strategija - užduotis, kuriai šiuolaikinès kariuomenès buvo prastai paruoštos igyvendinti (Rynning, Schmitt 2017: 4).

Dauguma naujuosius karus apibrèžiančių paradigmų siekia suderinti kariuomenès gebejjimą prisitaikyti tiek prie konvencinių, tiek prie nekonvencinių grèsmių (Evans 2009: 66). Generolas Charles C. Krulakas, apibūdindamas XXI a. mūšio lauką suformavo triju bloku karybos koncepciją:

Vienu metu mūsų kariai maitins ir rengs pabėgèlius, teikdami humanitarinę pagalbą. Kitu metu jie taikys dvi konfliktuojančias gentis igyvendindami taikos palaikymo operacijas ir, galiausiai, jie kovos mirtiname vidutinio intensyvumo mūšyje ir visa tai vyks tą pačią diena, trijuose miesto blokuose. Tai bus trijų blokų karas. Tokioje aplinkoje konvencinès [karybos] doktrinos ir organizacijos turi mažai ittakos. Tai pokyčių aplinka (Krulak 1997).

Apibrèždamas blokus, pirmąji Krulakas apibūdina kaip tradicinę konvencinę karyba, nors ir daro išlyga, jog skirtingai nei tradicinèje karyboje, kariaujančios 
šalys gali nenaudoti vienodų kovos taisyklių, pavyzdžiui, priešo kovotojai gali nesilaikyti karo teisès ir sąmoningai aukoti civilius ir šitaip konfliktą paversti asimetriniu. Antras blokas - taikos palaikymo ir kitos stabilizavimo operacijos. Trečias blokas - humanitarinè parama ir rekonstrukcija. Antro ir trečio bloko igyvendinimui reikalingas kariuomenès bendradarbiavimas su civiliais, iskaitant diplomatus, nevyriausybines organizacijas, vietos ir užsienio vyriausybių darbuotojus. Krulakas pabrėžia, jog nei vienas iš šių blokų neturi būti laikomas svarbesniu už kitus ar matomas kaip atskirų blokų karas, tai - kontinuumas, kuriame taikos blokas gali virsti kariniu veiksmų bloku, ir atvirkščiai. Taigi, , „vien tik technologiniai ar moksliniai sprendimai nebus tinkami šiandieniniams konfliktams išspręsti; taip pat jie negalès pakelti Clausewitzo vadinamojo karo rūko" (Krulak 1998: 48).

Jamesas Mattis ir Frankas Hoffmanas 2005 m. papilde Krulako koncepciją itraukdami kultūrini veiksni ir šitaip suformuodami keturiu bloku karybos koncepciją. Pastebėdami, kad hibridiniai karai, kaip ir mažieji karai, negali būti laimèti mūšio lauke, sutelkiant dèmesi tik i karines technologijas, trijų blokų karybos koncepciją jie išplečia pridèdami didžiausią bloką: karių kultūrinius mokymus. „Kariai turi suprasti vietovès kultūrini reljefą taip pat gerai, kaip kad supranta fizini vietovės žemèlapi" (Mattis, Hoffman 2005: 18-19). Ketvirtasis blokas karyboje skirtas didinti „intelektualią galią": paveikti šalies, kurioje vykdoma operacija, vietos gyventojus ir pasiūlyti jiems alternatyvą priešininkų skleidžiamai ideologijai (Borsani 2013: 378-379).

Karo tarp žmoniu perspektyvos pradi- ninkas generolas Rupertas Smithas pabrèžia, kad karas, koki žinojome, nebeegzistuoja, ir daro išvada, jog karo tarp žmoniu paradigma pakeitè industrinio karo paradigmą: aiškus karo ir taikos atskyrimas, akivaizdus tarpvalstybiniuose karuose, nebeegzistuoja (Smith 2006a: 17). Šis paradigminis poslinkis rodo, kad žmonės yra mūšio lauko dalis (Smith 2006b: 720). Civiliai gyventojai mūšio lauke vienu metu yra ir tikslas, ir uždaviniai, ir galimos priešiškos jẻgos. Taigi, žmonès yra mūšio laukas: tautos valia ir nuomonè lemia rinkimus, daro itaką politikams ir paveikia pajègų panaudojimą tiek vietos, tiek tarptautiniu mastu. „Šiandieninès tarptautinès operacijos vyksta tarp žmonių, o tai reiškia, kad informacija tapo valiuta. Karas nebėra priemonè sunaikinti priešininka, tai - priemonè pakeisti jo ketinimus" (Smith 2006a: 3).

Neicsitraukiant i diskusija, ar naujuosius karus aiškinančios paradigmos turi pranašumą prieš kitas, pavyzdžiui, konvencinès karybos ar revoliucijos karybos srityje paradigmas, verta pažymèti, jog naujuosius karus apibrèžiančios paradigmos išryškina, jog technologinè viršenybė negali užtikrinti karinès pergalès, todèl karyboje kariuomenè turi pritaikyti ne tik naujas technologijas, bet ir strategijas (Jacob 2015: 204). Vienas šių strateginių pokyčių apima kovos su sukilimu teorijų taikymą sprendžiant naujujų karų keliamus iššūkius, kurių svarbą itin išryškino strateginès JAV ir sajungininkų nesèkmès konfliktuose Irake ir Afganistane (Gray 2013: 85-88). Galima apibendrinti, jog naujuosius karus aiškinančios paradigmos aktualizavo poreiki suinstitucinti kultūrinį veiksni, kaip karių kultūrinių kompetencijų visumą, karinèse doktrinose. 


\section{KULTŪRINIS VEIKSNYS KAIP KARIŲ KULTÜRINIŲ KOMPETENCIJY̨ VISUMA}

Išplėstas karinių operacijų spektras, kaip atsakas i saugumo aplinkos pokyčius, pakeitè karių vykdomas funkcijas, o tai lėmè kultūrinio veiksnio skverbimąsi i karines doktrinas. Daugelio valstybiu kariuomenèse didesniu ar mažesniu mastu pradèti vykdyti kultūriniai mokymai kariams ir į karines doktrinas pradèta įtraukti karių kultūrinių kompetenciju poreiki (žr. Lietuvos karine doktrina 2016).

Kariuomenems įsitraukiant į rekonstrukcijos, humanitarines, saugumo, mokomąsias ir kitas operacijas, kurios nèra susijusios su tiesioginiais kariniais veiksmais, kariai, veikdami kitoje kultūrinèje aplinkoje, iš dalies prisiima ir diplomatu vaidmeni (Greene 2010: 960-961), tad greta tradicinès kario-kovotojo koncepcijos paplito kario-diplomato koncepcija (žr. Moscos 2000, 1992; Barnes 1993; Burke 2009). Kario-diplomato koncepcijos ištakos sietinos ne tik su Charleso Moscos suformuotu modeliu: dar $1974 \mathrm{~m}$. Jit Rikhye et al pabrèžè, kad visiems kariams, dirbantiems taikos palaikymo pareigūnais, nepriklausomai nuo turimo laipsnio, greta tradicinių taktinių mokymu, būtina igyti igūdžiu, nesusijusių su jègos naudojimu. „Taktas, diplomatija, argumentavimas derybose ar tarpininkaujant yra taikos palaikymo pareigūnu ginklai. <...> Kariai turi būti supažindinami su informacija, leisiančia suprasti konflikto ištakas, valstybès, kurioje vykdoma operacija, gyventoju ir ju grupiu santykius" (Rikhye 1974: 267). Rudolphas C. Barnesas atkreipia dèmesi $i$ "naujojo kario" vaidmens svarbą. Anot Barneso, „kariai, turintys kontaktą su vietos gyventojais, privalo būti tiek pat diplomatai, kiek jie yra kovotojai. <...> Kariai turi bū- ti supažindinami su šalies, kurioje vykdoma tarptautinè operacija, kultūra, jos normomis ir politika“ (Barnes 1993: 12).

Davidas M. Lastas, analizuodamas Kanados įsitraukimo i taikos palaikymo operacijas penkiasdešimties metu praktika, išryškino karių komunikacinių igūdžių reikšmę tarptautinių operaciju metu, atskiriant kovinius igūdžius nuo komunikacinių igūdžių (Last 1997: 87). $2007 \mathrm{~m}$. Kanados ginkluotuju pajęu Sausumos strateginiu koncepciju direktoratas (angl. Canadian Armed Forces Directorate of Land Strategic Concepts) paskelbẻ tyrima, kuriame pabrèžiama, jog siekiant atitikti įsitraukimo į plataus spektro operacijas reikalavimus, sausumos pajegų kariai turi turèti platų žiniu ir iggūdžiu spektrą. Taktinès kompetencijos ir individualūs bei kolektyviniai karybos iggūdžiai, tradiciškai apibrèžiantys karį-kovotoją, išplečiami, itraukiant kario-diplomato koncepciją. (Clermont 2015: 25-26).

Manytina, jog tiek karys-kovotojas, tiek karys-diplomatas atspindi kariuomenès veiklos spektro skirtingas puses: kario-kovotojo koncepcija vis dar išlieka svarbia vykdant karinius veiksmus, o kario-diplomato koncepcijos svarba išryškejja kariuomenėms vykdant nekarinius veiksmus. Kario kaip diplomato koncepcijos atsiradimas neiškreipia kario kaip kovotojo suvokimo ir nepakeičia diplomatu kariais. Diplomato vaidmens priskyrimas kariui leidžia geriau apibrèžti ir suvokti karių vykdomą politinę-komunikacinę funkciją bei būtinus iggūdžius, žinias ir gebejimus, įskaitant ir kultūrines kompetencijas, kuriuos karys privalo turèti prisitaikant prie besikeičiančio karybos pobūdžio ir kitos kultūrinès aplinkos. 


\section{IŠVADOS}

Saugumo aplinkos kaita po Šaltojo karo sąlygojo karinių operacijų spektro kaita, o naujų karybos paradigmų, analizuojančių neintensyvius karus, ịsitvirtinimas tiek akademiniame, tiek kariniame kontekste atspindi saugumo aplinkos suvokimo kaitą. Šiu paradigmų esminis skirtumas nuo ankstesniu - bandymas irodyti, kad technologinè viršenybė nebėra lemiamas veiksnys siekiant karinès pergalès. Šiuolaikineje karyboje kariuomenès turi pritai-

\section{Literatūra}

Antczak Anna. 2018. 'New' and 'Old' Wars - the Changing Dimensions of Warfare. Przeglad Politologiczny (3): 199-216.

Archer Sarah E. 2003. Civilian and Military Cooperation in Complex Humanitarian Operations. Military Review (March-April): 32-41.

Barnes Rudolph C. 1993. Military Legitimacy and the Diplomat-Warrior. Small Wars and Insurgencies (4:1): 1-28.

Bonnell Victoria E., Breslauer George W. 2002. Szanton David L. (ed.). The Politics of Knowledge: Area Studies and the Disciplines: 217-261. Berkeley: University of California Press.

Borsani Davide. 2013. Beyond Military Technology, the Cultural Dimension of Counterinsurgency Doctrines. Sofia University Press: Sofia.

Bredow Wilfried. 2006. Caforio Guiseppe (ed.) Social Sciences and the Military: An Interdisciplinary Overview: 87-100. Cass Military Studies: Routledge.

Buley Benjamin. 2007. The New American Way of War. Military Culture and the Political Utility of Force. LSE International Studies Series.

Burke Edward. 2009. Leaving the Civilians Behind: The 'Soldier-Diplomat' in Afghanistan and Iraq. PRISM (2): 27-46.

Clermont Francis. 2015. The Art of Being a SoldierDiplomat $\sim$ From an Implicit Role to an Explicit Function. Canadian Military Journal (15:2): 25-35.

Dorman Andrew M. et al. 2002. The Changing Face of Military Power. Joint Warfare in an Expeditionary Era. Palgrave Macmillan: UK. kyti ne tik naujas technologijas, bet ir strategijas, atspindinčias besikeičiančią saugumo aplinką. Vienas šių pokyčių kultūrinio veiksnio, kaip karių kultūrinių kompetencijų visumos, skverbimasis $i$ karines doktrinas, atspindintis kario-diplomato funkciju poreikị karyboje. Kariu kultūriniu kompetenciju itraukimas i doktrininius dokumentus žymi strateginio mąstymo pokyčius, kultūrą militarizuojant ir išnaudojant kaip dar vieną ginklą kare.

Evans Michael. 2009. The Twenty-First Century Security Environment: Challenges for Joint Forces. The RUSI Journal (154:2): 64-72.

Farrell Theo, Terriff Terry (ed.). 2002. The Sources of Military Change: Culture Politics and Technology. Boulder: Lynne Rienner Publishers.

Farrell Theo. 2005. The Norms of War: Cultural Beliefs and Modern Conflict. London: Lynne Rienner.

Footitt Hilary. 2016. War and Culture Studies in 2016: Putting 'Translation' into the Transnational? Journal of War \& Culture Studies (9:3): 209-221.

Greene Talya et al. 2010. The Impact of Culture Clash on Deployed Troops. Military medicine (175): 958-963.

Haass Richard N. 2010. War of Necessity, War of Choice: A Memoir of Two Iraq Wars. Simon \& Schuster.

Jacob Frank. 2015. The Theory of a Military Revolution: Global, Numerous, Endless? RUHM (6:3): 189-204.

Kaldor Mary. 2005. New and Old Wars: Organized Violence in a Global Era. DehraDun: Natraj.

Keegan John. 1994. A History of Warfare. New York: Vintage Books.

Kier Elizabeth. 1997. Imagining War: French and British Military Doctrine between the Wars. Princeton: Princeton UP.

Kilcullen David J. 2007. New Paradigms for 21stCentury Conflict. eJournal USA (12): 39-45.

Krulak Charles C. 1997. Three Block War. Vital Speeches of the Day (64:5): 139-141. 
Last David M. 1997. Theory, Doctrine and Practice of Conflict De-escalation in Peacekeeping Operations. Toronto: The Canadian Peacekeeping Press.

Lietuvos karine doktrina. 2016. Lietuvos kariuomenès Karo kartografijos centras.

Lind William S. et al. 2008. Terriff Terry et al. (ed.). Global Insurgency and the Future of Armed Conflict: Debating Fourth-Generation Warfare: 13-20. New York: Routledge.

Lynn John A. 2003. Battle: A History of Combat and Culture. Boulder: Westview Press.

Mattis James N., Hoffman Frank G. 2005. Future Warfare: The Rise of Hybrid Wars. Proceedings (November): 18-19.

Moscos Charles C. 2000. Moscos Charles C. et al (ed.), The Postmodern Military. Oxford: Oxford University Press.

Munkler Herfried. 2005. The New Wars. Cambridge: Polity Press.

Muunkler Herfried. 2003. The Wars of the 21st Century. International Review of the Red Cross (85:849): 7-22.

Petraeus David G. 2006. Learning Counterinsurgency: Observations from Soldiering in Iraq. Military Review (January-February): 2-12.

Pfanner Toni. 2005. Asymmetric Warfare from the Perspective of Humanitarian Law and Humanitarian Action. International Review of the Red Cross (87:857): 149-174.

\section{Nuorodos}

1 Richardas N. Haassas išskiria dviejų tipų karus: būtinuosius karus (angl. wars of necessity) ir pasirenkamuosius karus (angl. wars of choice). Būtinieji karai yra neišvengiami karai, apimantys valstybių nacionalinių interesų igyvendinimą ir status quo išsaugojimą. Būtinųjų karų pavyzdžiai: Antrasis pasaulinis karas, Korejos karas. Pasirenkamieji karai siejami su ne tokiais svarbiais valstybių interesams karais, todèl valstybès gali imtis alternatyvios politikos, siekiant išvengti karo, nesvarbu, ar tai būtų diplomatinès iniciatyvos, neveikimas ar kažkas kita. Pasirenkamųjų karų pavyzdžiai: Vietnamo, Bosnijos ir Kosovo karai (Haass 2010).

2 Karių kultūrinès kompetencijos - gebèjimai, užtikrinantys kariuomenès pajègumą vykdyti
Porter Patric. 2007. Good Anthropology, Bad History: The Cultural Turn in Studying War. $\mathrm{Pa}$ rameters (37:2): 45-58.

Rikhye Indar J. et al. 1974. The Thin Blue Line: International Peacekeeping and Its Future. New Haven: Yale University Press.

Rosen Stephen P. 1996. Societies and Military Power: India and Its Armies. Ithaca: Cornell University Press.

Rynning Sten, Schmitt Olivier. 2017. Gheciu, Alexandra, Wohlforth, William (ed.). Oxford Handbook of International Security. Oxford University Press.

Segal Hugh. 2005. Geopolitical Integrity. McGillQueen's University Press.

Smith Rupert. 2006a. Methods of Warfare. Interview with General Sir Rupert Smith. International Review of the Red Cross (88:864): 719-727.

Smith Rupert. 2006b. The Utility of Force: The Art of War in the Modern World. London: Penguin.

Spencer Emily. 2009. It's All About the People: Cultural Intelligence (CQ) as a Force Multiplier in the Contemporary Operating Environment. Journal of Conflict Studies: 96-106.

Zafar Morwari. 2016. COIN-operated Anthropology: Cultural Knowledge, American Counterinsurgency and the Rise of the Afghan Diaspora [PhD thesis]. University of Oxford.

karinę veiklą kitoje kultūrinejje aplinkoje ar susiduriant su kultūriniais skirtumais. Kultūrinès kompetencijos apima kultūros specifinit, tarpkultūrinị ir kalbos elementus. Kultūros specifini elementą sudaro žinios apie tam tikrą šalį, i̇skaitant ekonominę, religinę ir istorinę padètị, socialinę infrastruktūra, vietos populiacija, politika, nacionalines ir religines šventes, geografinę, klimatinę, topografinę padètị. Tarpkultūrinis elementas apima mokẻjimą šias žinias taikyti adaptuojantis ir veikiant kitoje kultūrinejje aplinkoje. Kalbos elementas apima kalbos, vyraujančios šalyje, kurioje vykdoma tarptautinè operacija, igūdžius, kurių trūkumas gali būti kompensuojamas darbo su vertèju igūdžiais. 